\title{
Penerapan Pendidikan Lingkungan Hidup Di Perguruan Tinggi Dengan Model Outdoor Learning
}

\author{
Muhammad Ali ${ }^{1}$, Muhammad Ardi², Suradi Tahmir ${ }^{2}$ \\ ${ }^{1}$ Program Studi Pendidikan Biologi, Fakultas Keguruan dan Ilmu Pendidikan STKIP Bone. \\ ali_ttpjkr@yahoo.co.id \\ ${ }^{2}$ PPS PKLH Universitas Negeri Makassar \\ nurlita.pertiwi@unm.co.id
} (http:/creativecommons.org/licenses/by-nc/4.0)

\begin{abstract}
.
environmental learning aims that students have concern for the surrounding environment. The learning model of environmental learning (EL) described in this article applies the outdoor learning method. Learning materials presented to students are arranged by involving the surrounding environment. This means that learning can be done not only in classrooms, but also outside the classroom in order for students to be more comfortable and active in the learning process. the initial ability of students needs to be considered in the learning process because it affects the ability of students to follow the next learning process. This article describes the meaning, goals and benefits, advantages and disadvantages and the stages of the method of outdoor learning. So that it can be concluded that higher education is education in higher education that has several general goals / principles where knowledge (knowledge) is created, used continuously and a place of search for knowledge, solving various problems, where to criticize the works produced, or as the place for the formation and development of student character to become a student who has high reasoning, sharp and broad analysis. Especially in environment-based learning developed so that students gain more experience related to the surrounding environment.
\end{abstract}

Keywords: environment, outdoor learning, learning, students

\section{PENDAHULUAN}

Salah satu jalur pendidikan lingkungan hidup adalah melalui pendidikan formal, yaitu pendidikan yang diselenggarkan di sekolah. Komponen utama dalam upaya pengembangan kemampuan, keterampilan, pengetahuan, sikap dan meningkatkan hasil belajar peserta didik (mahasiswa) adalah dosen pembimbing. Dosen mempunyai peran startegis dalam membangun perilaku mahasiswa, baik dalam hal pengetahuan, sikap, dan tindakan keterampilan mahasiswa. Perubahan pengetahuan, sikap, dan tindakan dapat dilakukan terutama melalui contoh-contoh, panutan, kegiatan nyata yang dapat dicoba, dialami, dan diusahakan oleh mahasiswa yang akan bermanfaat bagi kehidupan mahasiswa itu sendiri maupun juga bagi lingkungannya.

Dosen memiliki kesempatan yang luas dan peran yang penting dalam pembentukan perilaku peduli terhadap kualitas dan kelestarian lingkungan. Hal ini mengingat, kuantitas dan kualitas interaksi dosen dan mahasiswanya menjadi semakin intens. Beberapa persyaratan penting bagi dosen agar dapat menjalankan tugasnya dengan baik dalam proses pendidikan lingkungan hidup adalah: (a). Menguasai materi yang mendukung Pendidikan Lingkungan Hidup; (b). Mampu membuat Rencana Program Semester (RPS) sebagai wujud integrasi materi Pendidikan Lingkungan Hidup yang berpusat pada siswa (student centerd learning); (c) Memahami dan dapat menerapkan metode/cara pembelajaran yang dapat mendorong perubahan perilaku sadar dan peduli lingkungan secara menarik, berhasil guna, dan sesuai materi maupun karakteristik sasaran, dan (d) Memahami dan mampu menerapkan proses pembelajaran yang berpusat pada siswa dalam proses pendidikan lingkungan hidup, sehingga siswa dapat membangun sendiri dan memiliki pengetahuan, sikap dan perilaku sadar dan peduli terhadap lingkungan.

Perubahan pendidikan kearah yang lebih baik dapat dilakukan dengan berbagai upaya, diantaranya dengan menciptakan tempat yang baik dan ideal untuk memperoleh segala ilmu pengetahuan dan berbagai norma serta etika yang dapat menjadi dasar manusia menuju terciptanya kesejahteraan hidup dan menuju kepada cita-cita pembangunan berkelanjutan. Menciptakan kondisi 
yang baik bagi kampus untuk menjadi tempat pembelajaran dan penyadaran warga kampus, sehingga di kemudian hari warga kampus tersebut dapat turut bertanggung jawab dalam upaya-upaya penyelamatan lingkungan hidup dan pembangunan berkelanjutan.

Pembelajaran pendidikan lingkungan hidup semakin marak diterapkan di perguruan tinggi dengan tujuan adalah bukan mempekerjakan mahasiswa sebagai pekerja di lingkungan kampus, tetapi membangun jiwa cinta lingkungan, dengan harapan bahwa generasi berikut menjadi generasi yang berbudaya lingkungan dan menjadi sebuah habit bagi semua civitas akademik.Untuk maksud tersebut, kampus dan semua stake-holder serta pemerhati lingkungan hidup melakukan konsistentisasi yang holistik kepada konsumen pendidikan tentang peran lingkungan terhadap keberlangsungan kehidupan di bumi, ancaman terhadap kehidupan dan solusi penyelamatan kehidupan di bumi, serta menjelaskan tentang porsi perhatian kampus dalam hal ini mahasiswa terhadap ekosistim lingkungan hidup sekitarnya.

Untuk dapat memecahkan masalah lingkungan, pada prinsipnya ada tiga langkah utama yang dapat ditempuh, yaitu: Pertama menyadari adanya masalah. Sebenarnya setiap orang sudah tahu adanya masalah lingkungan yang ada di sekelilingnya, lokal, regional, nasional bahkan internasional tetapi semua kebingungan harus berbuat apa. Kedua, adalah analisis masalah untuk mengidentifikasi akar penyebab (root causes) munculnya masalah. Akar penyebab dari semua permasalahan lingkungan adalah: ledakan penduduk (overpopulation), konsumsi yang berlebihan (overconsumption), ketidakefisienan, prinsip linieritas, ketergantungan akan bahan bakar minyak, dan mentalitas untuk tetap mempertahankan kebiasaan. Ketiga, mengembangkan strategi untuk mengoreksi masalah yang ada dan mencegah terjadinya lagi di masa yang akan datang.

Upaya meningkatkan kualitas proses dan hasil belajar mahasiswa, para ahli pembelajaran menyarankan penggunaan paradigma pembelajaran konstruktivis untuk kegiatan pembelajaran secara teori dan praktek. Pembelajaran selalu diprioritaskan kepada mahasiswa. Kegiatan pembelajaran didesain sedemikian rupa agar lebih banyak melibatkan mahasiswa, mendorong mahasiswa untuk lebih kreatif dan belajar mandiri melalui model, pendekatan, strategi dan metode pembelajaran yang inovatif. Berdasarkan kondisi pembelajaran tersebut di atas, model pembelajaran yang diharapkan dapat meningkatkan pengetahuan dan sikap mahasiswa dalam mata kuliah PLH adalah dengan menggunakan model pembelajaran environmental learning yakni model pembelajaran yang berbasis lingkungan. Pembelajaran environmental learning yaitu pembelajaran yang memanfaatkan lingkungan alam sekitar sebagai sumber pembelajaran. Lingkungan sekitar merupakan sarana bagi mahasiswa, di mana mahasiswa dapat beraktivitas, berkreasi, berinovasi termasuk mengembangkan pikiran sehingga membentuk sikap baru dalam kegiatannya. Dengan demikian lingkungan sebagai tempat bereksplorasi, bereksperimen dan mengekspresikan diri untuk mandapatkan konsep dan informasi baru sebagai wajud dari hasil belajar (Kadir, 2016)

Model pembelajaran environmental learning merupakan pembelajaran berbasis lingkungan yang dikembangkan agar mahasiswa memperoleh pengalaman lebih berkaitan dengan lingkungan sekitar. Khoiriyah, L.F., (2015) menyatakan bahwa model pembelajaran lingkungan adalah model pembelajaran yang mengedepankan pengalaman mahasiswa dalam hubungannya dengan alam sekitar, sehingga mahasiswa dapat dengan mudah memahami isi materi yang disampaikan. Artinya, model pembelajaran environmental learning bertujuan agar mahasiswa memiliki kepedulian terhadap lingkungan sekitar.

Model pembelajaran environmental learning (EL) yang diuraikan dalam artikel ini penerapannya menggunakan metode outdoor learning. Bahan pembelajaran yang disajikan kepada mahasiswa disusun dengan melibatkan lingkungan sekitar. Artinya pembelajaran bisa dilakukan tidak hanya dalam kelas, tetapi juga diluar kelas dengan tujuan agar mahasiswa lebih nyaman dan aktif dalam proses pembelajaran. Setiap mahasiswa mempunyai kemampuan belajar yang berbeda-beda. Kemampuan awal mahasiswa adalah kemampuan yang telah dipunyai oleh mahasiswa sebelum mengikuti model pembelajaran yang akan diberikan. Kemampuan awal (entry behavior) ini menggambarkan kesiapan mahasiswa dalam menerima mata kuliah yang akan disampaikan oleh dosen. Kemampuan awal mahasiswa dapat berpengaruh terhadap suatu proses pembelajaran di dalam kelas, misalnya taraf intelegensi, daya kreativitas, motivasi belajar, tahap perkembangan, kemampuan berbahasa, sikap terhadap tugas, kebiasaan dalam cara belajar, kecepatan belajar dan kondisi fisik. Sehingga kemampuan awal yang dimiliki mahasiswa menjadi dasar untuk lebih mengembangkan pengetahuannya, sehingga kemampuan awal mahasiswa perlu diperhatikan dalam proses pembelajaran 
karena berpengaruh terhadap kemampuan mahasiswa dalam mengikuti proses pembelajaran selanjutnya. Artikel ini akan menguraikan tentang metode pembelajan outdoor learning yang diterapkan dalam pembelajaran lingkungan.

\section{Pengertian Outdoor learning}

Purnomo, A., (2017) menyatakan, outdoor learning process (OLP) adalah pembelajaran sains dengan melakukan petualangan di lingkungan sekitar dengan secara teliti yang hasilnya dicatat ke dalam Lembar Kerja Pengamatan (LKP).Barlet (dalam Husamah. 2013:20) menyatakan, model pembelajaran pendidikan luar ruang adalah suatu pembelajaran yang dilakukan di luar ruang atau luar kelas. Sedangkan Suherdiyanto, s., (2016) menyatakan, proses pembelajaran luar kelas adalah proses pembelajaran yang dapat membangun makna (input), kemudian prosesnya melalui struktur kognitif sehingga berkesan lama dalam ingatan atau memori (terjadirekonstruksi).

Outdoor learning senada pula dengan pendapat Paulo Freire (2002) yang mengatakan bahwa:every place is a school, everyone is teacher (setiap orang adalah dosen, dosen bisa siapa saja, dimana saja, serta hadir kapan saja, tanpa batas ruang, waktu, kondisi apapun). Hal ini menegaskan siapa saja dapat menjadi dosen dan pembelajaran tidak harus berlangsung di dalam kelas, sebab setiap tempat dapat menjadi tempat untuk belajar. Konsep Paulo Freire sangat tepat bila dihubungkan dengan metode outdoor learning. Outdoor learning dapat menjadi salah satu alternatif bagi pengayaan sumber pembelajaran.

Outdoor learning memberikan dorongan perasaan kebebasan bagi mahasiswa. Sebagai hasil dari tidak dibatasinya ruang berpikir mahasiswa oleh dinding-dinding kelas. Sebagaimana diungkapkan Nurfitriyanti, M., (2015) bahwa:thinking outside the box is sometimes difficult when students and teachers are working within the constraints of a traditional classroom. Students especially have their outlooks limited by classroom walls because they often do not yet have a wide perspective on the potential for their actions to have civic consequences. Yang artinya berpikir kreatif terkadang sulit ketika mahasiswa dan dosen belajar dengan ketidakleluasaan di dalam kelas tradisional. Hal tersebut dikarenakan pandangan yang dimiliki mahasiswa dibatasi dinding kelas sehingga mereka belum memiliki perspektif yang luas tentang potensi yang ada pada tindakan mereka sebagai konsekuensi agar dapat bermanfaat bagi kepentingan umum.

Beberapa pendapat di atas dapat disimpulkan bahwa outdoor learning adalah suatu kegiatan di luar kelas yang menjadikan pembelajaran di luar kelas menarik dan menyenangkan, bisa dilakukan dimanapun dengan menekankan pada proses belajar berdasarkan fakta nyata, yang materi pembelajarannya secara langsung dialami melalui kegiatan pembelajaran secara langsung dengan harapan mahasiswa dapat lebih membangun makna atau kesan dalam memori atau ingatanya.

\section{Tujuan dan Manfaat Metode Pembelajaran Outdoor Learning}

Tujuan pembelajaran di luar kelas (outdoor learning) yang secara umum ingin dicapai melalui aktivitas di luar ruang kelas atau di luar lingkungan kampus dalam Purnomo, A., (2017) adalah. 1) Membuat setiap individu memiliki kesempatan unik untuk mengembangkan kreativitas dan inisiatif personal; 2) Menyediakan latar (setting) yang berarti bagi pembentukan sikap; 3) Membantu mewujudkan potensi setiap individu agar jiwa, raga dan spiritnya dapat berkembang optimal; 4) Memberikan kesempatan bagi anak-anak untuk merasakan secara langsung terhadap materi yang di sampaikan; 5) Memungkinkan mahasiswa mengembangkan keterampilan dan ketertarikan terhadap kegiatan-kegiatan luar kelas; 6) Memberikan kontribusi untuk membantu mengembangkan hubungan dosen-mahasiswa yang lebih baik melalui berbagai pengalaman di alam bebas; 7) Memberikan kesempatan untuk belajar dari pengalaman langsung; dan 8) Memanfaatkan sumber-sumber yang berasal dari lingkungan dan komunitas sekitar untuk pembelajaran.

Sedangkan Purnomo, A., (2017), menyebutkan, bahwa manfaat pembelajaran luar kelas antara lain. 1) Pikiran lebih jernih;2) Pembelajaran akan terasa menyenangkan;3) Pembelajaran lebih variatif;4) Belajar lebih rekreatif;5) Belajar lebih riil;6) Anak lebih mengenal pada dunia nyata dan luas;7) Tertanam image bahwa dunia sebagai kelas;8) Wahana belajar akan lebih luas; dan 9) Kerja otak lebih rileks. 


\section{Kelebihan dan Kekurangan Metode Pembelajaran Outdoor Learning}

Menurut Uno, H., B. dan Nurdin Mohamad, (2011) konsep pembelajaran dengan menggunakan metode outdoor learning memiliki beberapa kelebihan, antara lain sebagai berikut. 1) Peserta didik dibawa langsung kedalam dunia yang kongkret tentang penanaman konsep pembelajaran, sehingga peserta didik tidak hanya bisa menghayalkan materi;2) Lingkungan dapat digunakan setiap saat, kapan pun dan dimana pun sehingga tersedia setiap saat, tetapi tergantung dari jenis materi yang sedang diajarkan;3) Konsep pembelajaran dengan menggunakan lingkungan tidak membutuhkan biaya karena semua telah disediakan oleh alam lingkungan;4) Mudah di cerna oleh pesrta didik karena pesrta didik disajikan materi yang sifatnya konkret bukan abstrak;5) Peserta didik akan lebih leluasa dalam berfikir dan cenderung untuk memikirkan materi yang diajarkan karena materi yang diajarkan telah tersaji didepan mata (konkret).

Sedangkan menurut Menurut Kurniawati, H.I., (2015) menjelaskan, banyak kelebihan yang diperoleh dari kegiatan mempelajari lingkungan dalam proses belajar, antara lain:1) Kegiatan belajar lebih menarik dan tidak membosankan mahasiswa duduk berja-jam, sehingga motivasi belajar mahasiswa akan lebih tinggi; 2) Hakekat belajar akan lebih bermakna sebab mahasiswa dihadapkan dengan situasi dan keadaan yang sebenarnya atau bersifat alami; 3) Bahan-bahan yang dapat dipelajari lebih kaya serta lebih faktual sehinggakebenarannya akurat; 4) Kegiatan belajar mahasiswa lebih komprehensif dan lebih aktif sebab dapatdilakukan dengan berbagai cara seperti mengamati, bertanya atau wawancara, membuktikan atau mendemonsrrasikan, menguji fakta, dan lain-lain; 5) Sumber belajar lebih kaya sebab lingkungan yang dapat dipelajari bisa beraneka ragam seperti lingkungan social, lingkungan alam, lingkungan buatan, dan lain-lain; dan 6) Mahasiswadapat memahami dan menghayati aspek-aspek kehidupan yang ada dilingkungannya, sehingga dapat membentuk pribadi yang tidak asing dengan kehidupan membentuk sekitarnya, serta dapat memupuk cinta lingkungan.

Menurut Kurniawati, H.I., (2015), kelemahan dan kekurangan yang sering terjadi dalam pelaksanaan kegiatan pembelajaran outdoor learning berkisar pada teknis pengaturan waktu dan kegiatan belajar, antara lain. 1) Kegiatan belajar kurang dipersiapkan sebelumnya yang menyebabkan ada waktu mahasiswa dibawa ke tujuan tidak melakukan kegiatan belajar yang diharapkan sehingga ada kesan main-main; 2)Ada kesan dosen dan mahasiswa bahwa kegiatan mempelajari lingkungan memerlukan waktu yang cukup lama sehingga menghabiskan waktu untuk belajar di kelas; dan 3)Sempitnya pandangan dosen bahwa kegiatan belajar hanya terjadi di dalam kelas.

\section{Tahap-tahap Metode Pembelajaran Outdoor Learning}

Menurut Purnomo (2017), tahap-tahap yang perlu dilakukan dosen dalam pelaksanaan pembelajaran di luar kelas (outdoor learning) terdiri dari tahap persiapan, tahap pelaksanaan, dan tahap evaluasi.

Tahap persiapan, meliputi:

a. Merumuskan tujuan pembelajaran

b. Dosen menyiapkan tempat dan media yang ada di luar lingkungan

c. Dosen mengajak mahasiswa ke luar kelas

d. Baik dosen maupun mahasiswa harus dalam keadaan nyaman, rileks dan tidak merasa terpaksa.

Tahap pelaksanaan, meliputi:

a. Dosen menginstruksikan kepada mahasiswa untuk berjalan dengan rapi dan tertib untuk belajar di luar kelas

b. Dosen berdiri berhadapan dengan mahasiswa berjarak kira-kira 1 meter Melaksanakan percakapan antara dosen dengan mahasiswa dan mahasiswa dengan mahasiswa

c. Dosen menjelaskan materi

d. Mahasiswa memperhatikan penjelasan dosen di luar kelas

e. Dosen memberikan kesempatan kepada mahasiswa untuk bertanya

Tahap evaluasi, meliputi:

a. Tahap evaluasi merupakan kesempatan yang diberikan dosen kepada mahasiswa untuk memperlihatkan kemajuannya.

b. Jika mahasiswa tidak memberikan jawaban maka dosen tidak mengatakan salah tetapi menyebutkan kata yang benar dan mengajak mahasiswa untuk mengulangi kembali.

c. Dunia perguruan tinggi merupakan tempat menyemai, mendidik dan melatih mahasiswa agar menjadi mahasiswa yang memiliki daya nalar tinggi, analisis tajam dan luas. Sayangnya perguruan 
UNM Environmental Journals, Vol.1 No.3 Agustus 2018 hal. Hal. 77-81

tinggi kurang memberikan porsi pada pembentukan karakter mahasiswa. Bahkan Asyanti, S (2012) menyatakan jika perguruan tinggi menjanjikan pembentukan dan pengembangan karakter mahasiswa seperti yang terjadi di Inggris, semua itu hanya retorika institusi universitas modern.

\section{KESIMPULAN}

Sehingga dapat disimpulkan bahwa perguruan tinggi merupakan pendidikan di jenjang pendidikan tinggi yang memiliki beberapa tujuan/prinsip umum dimana knowledge (pengetahuan) diciptakan, digunakan secara terus menerus dan tempat pencarian ilmu pengetahuan, pemecahan berbagai masalah, tempat mengkritisi karya-karya yang dihasilkan, maupun sebagai tempat pembentukan dan pengembangan karakter mahasiswa agar menjadi mahasiswa yang memiliki daya nalar tinggi, analisis tajam dan luas. Khususnya dalam pembelajaran berbasis lingkungan yang dikembangkan agar mahasiswa memperoleh pengalaman lebih berkaitan dengan lingkungan sekitar.

\section{REFERENSI}

Kadir, A., 2016. Pengaruh Model Pembelajaran IPA Berbasis Lingkungan dan Kemampuan Awal terhadap Peningkatan Pengetahuan dan Sikap Peserta Didik di MTs Kota Kendari(Doctoral dissertation, Pascasarjana).

Khoiriyah, L.F., 2015. Implementasi model environmental learning dalam mewujudkan kepedulian terhadap lingkungan pada siswa kelas IV di SDN Dinoyo 2 Malang (Doctoral dissertation, Universitas Islam Negeri Maulana Malik Ibrahim).

Purnomo, A., 2017. Pengaruh Pembelajaran Outdoor terhadap Pengetahuan, dan Sikap Pelestarian Lingkungan Mahasiswa S1 Pendidikan Geografi Universitas Kanjuruhan Malang. Jurnal Pendidikan Geografi: Kajian, Teori, dan Praktek dalam Bidang Pendidikan dan Ilmu Geografi, 20(1).

Suherdiyanto, s., 2016. Penerapan metode pembelajaran diluar kelas (out door study) dalam materi permasalahan lingkungan dan upaya penanggulangannya pada siswa mts al-ikhlas kuala mandor b. Sosial horizon: jurnal pendidikan sosial, 1(1), pp.95-108.

Freire, P., 2002. Sobre educação popular: entrevista com Paulo Freire. Educação popular: um encontro com Paulo Freire, 2, pp.67-108.

Nurfitriyanti, M., 2015. Pengaruh Kreativitas dan Kedisiplinan Mahasiswa terhadap Hasil Belajar Kalkulus. Formatif: Jurnal Ilmiah Pendidikan MIPA, 4(3).

Uno, H., B. dan Nurdin Mohamad, 2011. Belajar dengan Pendekatan PAILKEM, Bumi Aksara, Jakarta, ISBN, pp.978-602.

Kurniawati, H.I., 2015. Penerapan Metode Outdoor Study Untuk Meningkatkan Aktivitas dan Hasil Belajar IPA Siswa Kelas IV SD Negeri 01 Taji Tahun Ajaran 2014/2015 (Doctoral dissertation, Universitas Muhammadiyah Surakarta).

Asyanti, S., 2012. Pendidikan Karakter Di Perguruan Tinggi: Sudah Terlambatkah?. 